\title{
NIETZSCHE, EL NIHILISMO Y EL ARTE DE LA TRANSFIGURACIÓN
}

\author{
Nietzsche, the Nihilism and the Art of the Transfiguration
}

\author{
Eike Brock \\ Universidad de Bochum (Alemania)
}

\begin{abstract}
Resumen: El nihilismo es uno de los temas principales en el pensamiento de Nietzsche. Aunque Nietzsche no usa el término «nihilismo» en sí mismo desde 1880, el problema del nihilismo le molesta desde el comienzo de su carrera filosófica. Sin embargo, Nietzsche ya había desarrollado el concepto filosófico de una justificación estética eterna de la existencia en El nacimiento de la tragedia (1872), un concepto que es una respuesta a la amenaza del nihilismo, causado por el sufrimiento que la vida trae inevitablemente a su paso. En este primer libro la justificación se logra por medio del arte, es decir, una obra de arte especial: la tragedia de la antigua Grecia. No obstante, Nietzsche no es el único que proclama audazmente la muerte de Dios, también tiene que admitir con arrepentimiento la muerte de la tragedia. Por lo tanto, tiene que encontrar una nueva forma de evitar el nihilismo transfigurando la vida. De hecho, lo logra con la noción del «arte de la transfiguración». El presente texto examina los dos conceptos antinihilistas de transfiguración de Nietzsche en contraposición al trasfondo de su filosofía (también antinilista) del nihilismo.

Palabras clave: Nihilismo - muerte de dios - arte - trasnfiguración/ arte de la transfiguración
\end{abstract}

AвSTRACT: Nihilism is one of the major topics in Nietzsche's thinking. Even though Nietzsche does not use the term «nihilsm» itself bevor 1880 the problem of nihilism bothers him right from the beginning of his philosophical career. Yet Nietzsche had already developed the philosophical concept of an eternal aesthetic justification of existence in The Birth of Tragedy (1872)-a concept which is a response to the threat of nihilism, caused by suffering which life brings inevitably in its wake. In this early book the justification is achieved by means of art, i.e. a special work of art: ancient Greece's tragedy. However Nietzsche is not only the one to boldly proclaim the death of God, he also has contritely to admit the death of tragedy. Thus he has to find a new way to avert nihilism by transfiguring life. Indeed he succeeds in this task with the notion of the «art of transfiguration». The present text scrutinizes both of Nietzsche's antinihilistic concepts of transfiguration against the backdrop of his (also antinihilistic) philosophy of nihilism.

Keywords: nihilism - death of god - art - transfiguration/art of transfiguration 


\section{UNA INTRODUCCIÓN CON FRIEDRICH DÜRRENMATT: DE LOS JUECES Y SUS VERDUGOS, ES DECIR, DE LOS NIHILITAS Y SUS ASESINOS}

La novela policíaca de Friedrich Dürrenmatt, El juez y su verdugo (1950/51) no solo cautiva por su protagonista carismático: el singular comisario Bärlach, que no desprecia la buena comida ni el vino excelente, aunque sufra de una enfermedad estomacal mortal ${ }^{1}$. La novela es interesante ante todo desde el punto de vista filosófico. En El juez y su verdugo no solamente se trata de un caso de asesinato, sino también, y a su vez, de un duelo sobre distintas visiones del mundo, o, si se prefiere, de filosofías. El origen del acontecimiento dramático, como en el Fausto de Goethe, es una apuesta diabólica. Esta apuesta que hacen Bärlach y su contrincante Gastmann, nace del espíritu de la Filosofía, que aquí, se vuelve a presentar según el modelo fáustico, como un espíritu tentador. La escena final de la novela es una mirada retrospectiva: hace más de 40 años se produjo en un tugurio cualquiera de Estambul una discusión filosófica entre Bärlach y Gastmann. El asunto de la discusión era el papel del azar en el acontecer del mundo ${ }^{2}$. Ciertamente, ambos contendientes estaban de acuerdo sobre una cosa, que el azar tiene necesariamente un papel fundamental, porque impulsado por sus caprichos espontáneos, evita notoriamente la predictibilidad del decurso del mundo. Pero ellos, movidos por el ardor infernal de los aguardientes, sacan distintas consecuencias de este hallazgo. Concretamente, se trata de la pregunta de qué consecuencias se sacan del dominio de la casualidad para la criminalística. «Tu tesis era - recuerda Gastmann - que la imperfección humana, el hecho de que no podamos predecir con certeza la forma de actuar de los demás ni tampoco logremos que el azar, que interviene en todo, se integre en nuestros cálculos, es la causa que acaba sacando irremisiblemente a la luz la mayoría de los crímenes. Dijiste que cometer un crimen era una estupidez porque es imposible mover a la gente como si fueran piezas de ajedrez. Yo, en cambio, sostuve la tesis, más por contradecirte que por convencimiento propio, de que precisamente lo intrincado de las relaciones humanas ofrecía la posibilidad de cometer crímenes que no pudieran ser descubiertos y, por ello, la gran mayoría de los delitos no solamente quedaban impunes, sino que ni siquiera llegaban a conocerse, como algo que ocurriera en el mayor de los secretos.»

1 El comisario Dürrenmatt es un criminalista intempestivo, que prefiere confiar antes en sus instintos, que en los métodos de criminalista más recientes fundados científicamente. Esto es tanto más notable, cuando Bärlach en su juventud se consideraba un reformador criminalista y fue utilizado también como tal (cf. Dürrenmatt 1992, 65).

2 Esta es una de las preguntas clave, en las que Dürrenmatt en su obra investiga una y otra vez, tanto en sus dramas, narraciones y novelas como también en sus escritos dramáticos teóricos y ensayos filosóficos. La discusión más intensa con la temática probablemente la ha planteado Dürrenmatt en sus siguientes novelas negras, en Das Versprechen (1958). 
(Dürrenmatt 1992: 65ss.) Del caldo de cultivo de esta contradicción surgía ahora - a la luz de una luna como «una luna informe y amarilla como un trozo de queso suizo» (Ibid.: 65) - la fatal apuesta «que puso al cielo por testigo» (Ibid.: 67), que era posible a Gastmann cometer un crimen en presencia de Bärlach, sin que este pudiese demostrárselo más tarde. Pero Bärlach considera la apuesta como «una broma terrible», que no se deja suprimir a causa del efecto inesperado. (cf. Ibid.: 67); Gastmann, sin embargo, la tomó en serio y asesinó tres días más tarde, ante los ojos de su amigo, a un hombre. De repente, $\mathrm{y}$ en apariencia completamente desmotivado, lo tiró por un puente. Y realmente el estupefacto Bärlach no estaba en condiciones de declarar culpable de asesinato a Gastmann, que se había convertido ahora en un criminal y en su enemigo mortal. Desde ese día Bärlach se propuso como tarea vital hacer responsable a Gastmann de esta acción y de todas las acciones sucesivas - que siempre fueron «más temerarias», «más salvajes», «más blasfemas». (Ibid.: 69). Finalmente, consigue juzgar a Gastmann, pero solo en la medida en que él se deshace de las premisas de su tesis: solo cuando Bärlach comienza a operar con hombres como con figuras de ajedrez, está en condiciones de rematar a Gastmann. El punto irónico de la novela está entonces en que Gastmann precisamente se convierte por el momento en el vencedor de la apuesta, cuando Bärlach consigue hacerle responsable. Eso solo fue posible, porque Bärlach firmó la filosofía de Gastmann, por decirlo así, con su sangre, cuando él se le abalanzó al cuello al asesino Tschanz (el verdugo del juez Bärlach). Tschanz es la figura del ajedrez de Bärlach. En una partida de ajedrez mortal él desempeña, en cierta medida, la figura del asesino, que se deja mover más flexible que la dama - por todo el tablero y de este modo confirma con una ejecución literal la «frase asesina» nihilista: «Nada es verdadero, todo está permitido» ${ }^{3}$. Naturalmente, todavía es más apropiado que Bärlach, con la introducción de Tschanz como figura de asesino, reaccione a la filosofía de Gastmann, que propaga una conducta en el marco de la frase del asesino. Por lo tanto, no es Bärlach el que primero mueve ficha en el terrible juego con Gastmann. En su forma original es la frase del asesino de Gastmann y no el credo de Bärlach. Este último es solo una variación del original, del que se deduce. El credo de Bärlach reza así: «Cuando nada más ayuda, todo está permitido». Sin embargo, todo esto no cambia nada para que al final el comisario se rinda ante la filosofía del criminal. Y justamente eso es lo que seduce y lo subversivo en El juez y su verdugo. Tenemos entre manos una

3 La llamada «sentencia de los asesinos», es decir, el Credo de los asesinos aparece en la obra de Nitezsche en varios lugares con perspectivas e interpretaciones distintas. Cf. en obras publicadas: GM III 24; Z IV «La sombra» y en FP III: 25[304]; 25[322]; 26[25]; 31[51]; 32[8]. 
novela en cuyo final solo aparentemente el bien mantiene la supremacía, mientras que lo que triunfa en realidad es el nihilismo.

La novela comienza con el descubrimiento de un asesinato en la provincia de Suiza, guiado por el informe de un asesinato que tuvo lugar en Estambul, y termina con la muerte de Gastmannn por Tschanz y con su hipotético suicidio de nuevo en la tranquila Suiza. Profundizando más, la novela trata también del hecho categórico, que aunque no parece situarse en un lugar y tiempo exactos, abarca y estremece como una marejada a todo el occidente. Se trata de la muerte de Dios, a la que Nietzsche alude en el famoso aforismo 125 de La gaya ciencia como un asesinato. Según las «pesquisas» de Nietzsche se trata con ello de una colectividad particular, en la que todos nosotros estamos involucrados: «Nosotros lo hemos matado, - ¡vosotros y yo! ¡Todos nosotros somos sus asesinos!» (FW 125, OC III 802; KSA 3, 481). De la complicidad de Bärlach en el caso del asesinato de «Dios» ya no se puede dudar, como muy tarde a partir de su reacción indirectamente afirmativa sobe el credo de asesinos de Gastmann ${ }^{4}$. Por eso, Bärlach se diferencia de Gastmann en que este entiende la muerte de Dios como una liberación de las cadenas de la moral, que colma, según Nietzsche, una serenidad insospechada (FW 343, OC III 858) ante un horizonte de posibilidades humanas que se abre ahora, un cómplice contra su voluntad. En el espacio sin Dios a él le ha ido mejor que al hombre loco de Nietzsche, que ante la muerte de Dios tiene miedo y angustia. En una cascada de preguntas sugestivas el hombre loco expresa la inquietud que produce el nihilismo, que se introduce con la muerte de Dios: «¿Hacia dónde no movemos nosotros? ¿Lejos de todos los soles? ¿No nos precipitamos permanentemente? ¿Y también hacia atrás, hacia adelante, hacia todos los lados? ¿Hay aún un arriba y un abajo? ¿No erramos como a través de una nada infinita? ¿No sentimos el hálito del vacío? ¿No hace más frío? ¿No viene continuamente la noche y más noche?» (FW 125, OC III 802; KSA 3, 481) Con la muerte de Dios se produce un desgarro en el mundo. Se quebranta la vieja estructura del orden. Orientarse en el mundo se convierte por ello en un problema. Según el diagnóstico de Nietzsche la dimensión y

4 Cuando Bärlach confronta a su adversario con el hecho de haberle condenado a muerte, uno podía pensar que el comisario intentase legitimar su oficio inoficial de juez mediante una referencia a Dios, y con ello a una verdad suprema: «Ya te he juzgado, Gastmann, y te he condenado a muerte. No pasarás del día de hoy. El verdugo que he elegido irá a verte hoy mismo. Te matará, porque es algo que hay que hacer algún día, en nombre de Dios» (Dürrenmatt 1992, 100). Sin embargo, me parece que la apelación de Bärlach al nombre de Dios no es tanto una expresión de fe como una frase, que él utiliza no sólo en ete lugar (cf. también p. 81). Bärlach utiliza la frase de Dios para poner el mayor énfasis posible en sus propias palabras. La apelación a Dios, es decir, la invocación a Dios no se dirige, por decirlo así, hacia lo alto en el ámbito transcendente, sino hacia el interior en la inmanencia del las propias convicciones. Es una autoafirmación, la que confirma su muerte en la aparente invocación de Dios. 
el carácter explosivo del problema todavía no ha sido reconocido ${ }^{5}$ : «Este acontecimiento monstruoso está todavía en camino y se desplaza, - no ha llegado aún a los oídos de los hombres. El relámpago y el trueno necesitan tiempo, la luz de ls estrellas necesita tiempo, los actos, para ser vistos y oídos, necesitan tiempo aún después de haber sido realizados. Este acto les sigue siendo más lejano que las estrellas más lejanas - ¡y sin embargo lo han hecho ellos mismos!» (Ibid.: 803). Por eso, muchos hombres tienen un fino instinto para acontecimientos formidables, cuyo significado la gran masa todavía ni se los ha planteado. También se dan cuenta de que están enredados en el curso del mundo. Ellos presienten, que no solo están condenados a ser observadores pasivos, cuando ven que el curso de la historia pasa rápidamente, sino que como seres históricos son responsables del lugar de los débiles; además ellos mismos participan en el viaje. De este modo, en el caso de la muerte de Dios, experimentan en sí mismos la conmoción de sus propios actos. Es posible que sucumban a ellos, pero también, que traten de crecer por sí mismos ante la grandeza de su propia acción. Eso también puede volver a suceder de una manera y una forma distintas. Gastmann es un asesino de Dios que tiene conciencia de sí mismo, que se inmerge lleno de entusiasmo en el vacío de Dios para llegar a ser él mismo un Dios, cuyo reino está más allá del bien y del mal. También Bärlach parece sentir la muerte de Dios en su propia carne. El hecho de que esté finalmente preparado para aplicarse a sí mismo métodos criminales para coger a un criminal, puede leerse como un intento desesperado de aceptar las consecuencias nihilistas de la muerte de Dios, que se hacen palpables a través de Gastmann. El nihilismo debe mantenerse a raya bajo todas las circunstancias, es decir, su abierta irrupción con la que Nietzsche relaciona una «lógica mostruosa del terror [...] un oscurecimiento y un eclipse de sol como probalemente no ha habido aún igual sobre la tierra (FW 343, OC III 858, KSA 3, 573), debe al menos ser demorada ${ }^{6}$. Gastmann es la personificación del nihilismo que surge - no es casual que a él se le nombre en la novela expressis verbis como nihilista ${ }^{7}$. En este contexto el nombre de

5 Cf. Sobre las consecuencias de la muerte de Dios, Brock 2015, 273-280.

6 Nietzsche ha reflexionado intensamente sobre los distintos tipos y formas de fenómenos del nihilismo. Una muestra de ello es ante todo sus anotaciones de mediados de los años 80 . Sobre la base de estos apuntes, así como de sus reflexiones de la obra publicada puede reconstruirse una especie de tipología nietzscheana, que Nietzsche mismo, sin embargo, no ha pensado finalmente de manera sistemática. Sobre una tipología semejante cf. Brock 2015, 288-311. Si es cierto que Bärlach quiere impedir la irrupción del nihilismo o al menos demorarla, aunque él mismo hace uso de medios nihilistas, entonces el comisario sería el representante del nihilismo incompleto, pues «el nihilismo incompleto se defiende (más o menos conscientemente) frente al ocaso del nihilismo, él aspira todavía a evitar el nihilismo, aunque ya se agarra a uno» (Müller 2015, 129).

7 En relación con la fuerza de atracción asombrosa de Bärlach hacia Gastmann, responde un escritor conocido de Gastmann: «Lo que me fascina de él [...] es la posibilidad de que un hombre sea 
Gastamann es significativo. Realmente Gastmann no es su verdadero nombre, sino solo un pseudónimo. Es el único nombre que él actualmente utiliza (Cf. Dürrenmatt 1992: 64). Nosotros no sabemos ni cuál es el nombre de pila de Gastmann ni cuántos ni qué nombres utilizó ya en el trascurso de su vida. Sin embargo, una cosa está clara: el nombre Gastmann es una elección afortunada. Viene como anillo al dedo para un nihilista como Gastmann ${ }^{8}$, en la medida en que él nunca está dispuesto a preocuparse por el mundo con una especie de obligación interior. Él prefiere estar distante (del mundo). El mundo nunca será para él su patria, siempre será un huésped. Parece como si el duelo asesino con Bärlach fuera la más íntima relación que Gastman ha mantenido con otros hombres desde aquella apuesta. Gastmann, sin embrago, es también en el ámbito semántico una buena elección del nombre. Pues él es un significante vacío, una especie de nombre vicario, un marco meramente formal, que se puede rellenar continuamente con contenidos discrecionales: Gast-Mann, eso recuerda al nombre vicario burocrático como Max Mustermann y Maximiliana Musterfrau. Finalmente el nombre del nihilista Gastmann se refiere también a una conocida expresión de Nietzsche, cuando habla una vez del nihilismo como al «más inquietante de todos los huéspedes» (FP IV 114, 1885 2[127], KSA 12, 125). Y realmente es difícil imaginar un huésped más inquietante que Gastmann. ¿A quién le gustaría tener a alguien en casa, que, completamente desconcertante, «por puro capricho, es capaz de hacer tanto el bien como el mal?» (Dürrenmatt 1992, 81). ¿A Quién le gustaría tener a alguien como huésped, que ciertamente es ingenioso y culto, que además disfruta del reconocimiento social y dispone de una experiencia rica, de la que se puede sacar tema de conversación para toda una vida, del que además, sin embargo, nunca se debe confiar y al que es mejor no darle la espalda, porque se toma la «libertad de la nada»? (Ibid., 83)

\section{De LOS HUÉSPEDES INQUIETANTES: NIETZSCHE Y EL PROBLEMA DEL NIHILISMO}

El discurso de Nietzsche sobre el huésped sumamente inquietante no deja de ser él mismo inquietante, si se le considera en su conjunto. En 1885, otoño/invierno (la estación del año fría y húmeda, inhóspita, y en este sentido nihilista ${ }^{9}$ ), escribe él en su cuaderno de notas: «El nihilismo está a las puertas:

realmente un nihilista [...] Siempre causa impresión encontrarse con una consigna hecha realidad». (Dürrenmatt 1992, 82).

8 No es sencillo dar una definición exacta del nihilismo, desde la que se pueda definir de nuevo exactamente qué es lo que distingue a un nihilista como tal. El autor tiene razón cuando caracteriza el nihilismo como una expresión de moda (cf. Nota 6). Sobe la historia del concepto de nihilismo ver apartado II, 1.

9 Sobre el invierno: «Aquí hay nieve, la vida ha enmudecido; las últimas cornejas a las que 
¿de dónde nos llega éste, el más inquietante de todos los huéspedes?»-(FP IV 114, 1885 2[127], KSA 12, 125). Éste, el más inquietante de todos los huéspedes posibles - el huésped, al que uno no le gustaría tener como tal - no se acaba de poner en camino hacia nuestra casa, sino que hace tiempo que ha recorrido el trayecto del camino hasta nosotros. Está ya ante nuestra puerta. $\mathrm{Su}$ visita es ya inminente. Por eso es ya demasiado tarde para cerrar las puertas y las ventanas, echar las cortinas y apagar la luz, para hacer como si no hubiera nadie en casa. No tiene ningún sentido disimular y esperar, hasta que vuelva a desaparecer el huésped decepcionado y frustrado. Pues el más inquietante de todos los huéspedes ni se deja engañar de cualquier manera ni está dispuesto a que se le rechace. Al final el nihilismo conseguirá entrar. Tampoco hay que descartar, que cuando el huésped haya entrado una vez vuelva a salir, o si él una vez dentro nunca más se moverá de allí. Por eso, primero ha asumido que el camino es demasiado largo y, en segundo lugar, que no tiene casa a la que pueda volver. El nihilismo es una inquietante prueba de que él mismo no tiene ningún hogar. Pero, retomemos de nuevo a la nota de Nietzsche « ¿De dónde nos viene este el más inquietante de todos los huéspedes?». La nota proporciona la respuesta a la pregunta misma, en cuanto que señala un esbozo simplista del origen del nihilismo. Con su origen es tratada al mismo tiempo la esencia del nihilismo, aunque muy toscamente. Nihilismo es, se dice en la nota: «el rechazo radical del valor, del sentido, de la deseabilidad» (Ibid.). Pero este rechazo no es debido a «situaciones de miseria social o de "degeneraciones fisiológicas" o incluso a la corrupción como causa del nihilismo», sino que el nihilismo está «en una interpretación completamente determinada» del mundo, es decir, de todo lo que es el caso y precisamente en «la interpretación cristiano-moral» (Ibid.).

La tesis que, según el nihilismo, se enraíza en la interpretación del mundo cristiano-moral, la ha expuesto Nietzsche en los años 1880 repetidas veces y la ha formulado desde distintos puntos de vista. El texto más significativo sobre el nihilismo no es, por eso, la nota llena de fantasía del más inquietante de todos los huéspedes, sino el llamado «fragmento Lenzer-Heide» Der europäische Nihilismus (FP IV 164, 1886 5[71], KSA 12, 211-217) En este fragmento Nietzsche narra en 16 breves apartados la historia del nihilismo

aquí se oyen dicen: “¿Para qué?”, “¡Para nada!”, ‘Nada!” — aquí ya nada crece ni florece [...]» (GM III 26, OC IV, KSA 5, 406). A Nietzsche frecuentemente le gusta usar como ilustración ideas de fuerte impacto e imágenes efectistas. Cuando se trata del nihilismo, Nietzsche lo ha hecho con paisajes especialmente áridos, como por ejemplo el desierto («El desierto crece: jay de aquel que encierre desiertos! La piedra cruje contra la piedra, el desierto engulle y estrangula» DD 3, OC IV 883, KSA 6, 387), pendientes profundas (DD 6, OC IV 887-888, KSA 6, 389-392; sobre esto cf. Brock 2017), paisajes montañosos inhóspitos (cf. Z III «La visión y el enigma», OC IV 166, KSA 4, 198; cf. Sobre esto, Brock 2015, 363) o valles desolados, es decir, lugares de la muerte. (Z IV «El hombre más feo», OC IV 235, KSA 4, 327). 
europeo. Mucho de lo que el fragmento desarrolla con cierta rapidez, vuelve a surgir más tarde de una forma más elaborada en la obra publicada de Nietzsche. En la agenda filosófica de Nietzsche ${ }^{10}$, sobre todo en La Genealogía de la moral y El Anticristo, se relaciona el problema del nihilismo con la moral y el cristianismo. Sin embargo, su posición de rechazo o negación del mundo nihilista está presente en él mucho antes, fundamentalmente a partir del comienzo de su creación filosófica. En verdad, Nietzsche solo utiliza el concepto de «nihilismo» a partir de 1880: «El consuelo de Lutero cuando la cosa no iba adelante, "el fin del mundo". Los nihilistas tenían a Schopenhauer de filósofo. Todos los que son extremadamente activos, cuando se dan cuenta de que sus deseos son imposibles [de realizar], desean que el mundo se deshaga en pedazos (Wotan)» (FP II 563, 1880 4[103], KSA 9, 125). Nietzsche, sin embargo, se ocupa más o menos ininterrumpidamente del problema de la negación del mundo desde que conoce la obra de Schopenhauer en 1865 de este modo los nihilistas tenían como filósofo no solo a Schopenhauer, sino también a Nietzsche. ${ }^{11}$ Nietzsche está de acuerdo con Schopenhauer en que la vida significa siempre sufrimiento. Pero discrepan los dos filósofos sobre las consecuencias que hay que sacar de este diagnóstico. Mientras que Schopenhauer a causa de las premisas morales no puede tolerar un mundo del sufrimiento, y por eso pone el énfasis en la negación del mundo a través de la ascesis de la voluntad y una lenta mortificación de la voluntad - en todo caso en teoría -, Nietzsche a pesar de todo quiere afirmar la vida. Él cuestiona en bloque el pesimismo de Schopenhauer, sin rechazar la ecuación cardinal pesimista de la vida como sufrimiento. Pero ¿debe realmente el pesimismo del sufrimiento sensible conducir al nihilismo de la negación del mundo? ¿Es, pregunta Nietzsche, «el pesimismo necesariamente el signo del declive, de la ruina, del fracaso, de los instintos fatigados y debilitados?», o ¿se puede pensar también en un «pesimismo de la fortaleza» (GT Ensayo de autocrítica, 1, OC I 329, KSA 1, 12) que afronta desafiante el sufrimiento y culmina en la afirmación del mundo «quizás desde el placer, la fuerza, desde una salud desbordante, y una plenitud sobremanera grande»? (GT prólogo 4, OC I 332, KSA 1, 16).

10 En El Anticristo Nietzsche sostiene ya casi formalmente: «Nihilista y cristiano [Nihilist und Christ]: ambas palabras tienen la misma rima, no solo tienen la misma rima» (AC 58, OC IV 765, KSA 6, 247).

11 Cf. Sobre el conocimiento de Nietzsche de la filosofía de Schopenhauer, en Brock 2015, 59-66. Un estudio que repasa meticulosamente la relación de Nietzsche con Schopenhauer a partir de 1865 hasta el final de la creación filosófica de Nietzsche ha sido presentado recientemente por Martin Morgenstens. El autor llega a la conclusión de que Schopenhauer ha «ejercido sobre Nietzsche una influencia grande y decisiva» y que especialmente las «reflexiones de Nietzsche sobre metafísica y ética $[. .$.$] frecuentemente sólo son comprensibles si tenemos en cuenta las ideas de Schopenhauer»$ (Morgenstern 2018, 231). 
Nietzsche, como es sabido, ha visto en la tragedia griega la expresión artística de un tal pesimismo de la fortaleza y en conexión con él intenta en su opera prima filosófica, El nacimiento de la tragedia (1872), una justificación estética de la existencia. La intención fundamental de la filosofía de Nietzsche ha sido siempre, por lo tanto, la afirmación del mundo y de la existencia. La voluntad del sí se mantiene a lo largo de la obra de Nietzsche y también, cuando él piensa el cristianismo o la moral occidental acuñada cristianamente con una crítica destructiva, con un no también devastador. El no de Nietzsche es válido para las tendencias nihilistas de la cultura occidental, las cuales impiden en su opinión un sí a la existencia y al mundo. Su no es, por lo tanto, una llave para el sí, expresado en otros términos, se quebranta de una manera afirmativadialéctica. ${ }^{12}$ La historia del nihilismo (europeo) comienza para Nietzsche no solo con el triunfo del Cristianismo, sino ya con el ocaso de la tragedia griega. A continuación quisiera en primer lugar resumir brevemente la historia del nihilismo europeo desde la perspectiva de Nietzsche. Con ello sin embargo, el capítulo del nihilismo todavía no está finalizado y eso porque al complejo de temas del nihilismo pertenece también el intento de Nietzsche de superar el nihilismo. Antes de que hable de ese intento, y para que en cierta medida pase a la parte terapéutica de la filosofía de Nietzsche, hay que tratar todavía otro aspecto del lado del diagnóstico. El nihilismo no solo es un fenómeno cultural, cuya historia se puede describir y contar, sino que por encima de ello tiene que ver esencialmente con el hombre en cuanto hombre. Se funda, es mi convicción, en el hombre mismo, en su «mismidad» (Selbsthaftigkeit)». Con otras palabras, el nihilismo tiene también una raíz antropológica. De ahí que Nietzsche sea consciente de la duplicidad causante del nihilismo, es decir, el hecho de que no pierda de vista tanto su dimensión cultural e histórica como también su dimensión antropológica, muestra un programa de Nietzsche de superar el nihilismo. Además se trata de un programa de afirmación, que se puede entender mejor como arte de la transfiguración y cuya fórmula reza así: Amor fati. Los apartados siguientes del presente artículo tratan de la duplicidad que causa el nihilismo, primero desde una perspectiva del diagnóstico y segundo desde un punto de vista terapéutico.

12 Cf. también Brock 2015, 4-7. En este pasaje permítaseme una rectificación: Es absolutamente absurdo afirmar ante este trasfondo, que cuando yo hablo de la filosofía de Nietzsche de la afirmación, me referiría a ese pasaje de la obra de Nietzsche, que «verbalizaría el sí a la vida explícitamente» Cf. Kast 2019, 25). Este reproche tampoco será justo, si se repite (cf. Ibid. 125) De la falta de capacidad de lectura en este contexto también se muestra la falta de atención que yo presto a El nacimiento de la tragedia en Brock 2015, 77-184 (cf. Kast 2019,40). Brock se queja de que su atención a «El nacimiento de la tragedia» fue desdeñada por Kast. 


\section{II.1 EL ORIGEN, ES DECIR, LA HISTORIA DEL HUÉSPED INQUIETANTE O: EL NIHILISMO COMO FENÓMENO CULTURAL}

En el transcurso de su bien documentada historia (del concepto) el nihilismo sirvió como denominación «en parte para puntos de vista y orientaciones filosóficas distintas» (Müller-Lauter 1984, 846). Realmente es muy grande el espectro de aquello que se acordó bajo la palabra clave de «nihilismo». Las huellas más antiguas del concepto las encontramos, siguiendo la línea teológica de la tradición, en el contexto de cuestiones relativas a la creación. Según las reflexiones correspondientes, si un creador puede crear algo de la nada (creatio ex nihilo), debería también estar en condiciones de volver hacer de algo nada, es decir, producir una aniquilación. El nihilismo que se basa en la aniquilación es en su radicalidad lo mismo que una «nulidad» completa, insuperable, pues «annihilatio» no quiere decir solo destrucción, transformación o disolución en parte de un objeto, sino su «desaparición». Teólogos o filósofos como Tomás de Aquino indican sin embargo, que una posibilidad (aquí: de la aniquilación) no es todavía una realidad (cf. Ibid., 376); a lo cual se suma en la Biblia la confianza documentada en la voluntad de Dios en la conservación de la creación. (cf. Ibid., 375), de manera que la idea de la aniquilación significaba en su época menos una amenaza existencial de lo que uno hoy podía presuponer frente a su contenido radical ${ }^{13}$. La aniquilación se «aniquila a sí misma», por decirlo así, en el marco de la historia sagrada cristiana. Como concepto y palabra clave filosófica el nihilismo hace su aparición mucho más tarde, o sea, en la época del idealismo alemán. Además es ante todo objeto de crítica una filosofía transcendental como la de Fichte centrada en el sujeto. Friedrich Heinrich Jacobi define su «interpretación idealista de la realidad como nihilista», en la medida en que en ella «la única realidad es el Yo, mientras que todos los otros llamados entes solo son representaciones del Yo, por lo tanto no siendo autónomos y por consiguiente nada (no tienen valor)» (Weischedel 1983 (Bd. 2), 162). Jacobi atribuye a Fichte la defensa de un nihilismo ontológico. Para Jacobi el idealismo de cuño fichteano practica una disolución del mundo en un solipsismo enamorado del yo, para el que finalmente después de todo también el yo debe ser sospechoso (cf. Ibid.: 163). El debate en torno al nihilismo ontológico es naturalmente de gran importancia para el concepto de nihilismo filosófico. Para el nihilismo como lema, que también encuentra aplicación más allá del ámbito filosófico, es, sin embargo,

13 En una versión secularizada aparece la idea en Günther Anders (2010, 294-306). Anders pone de relieve que el hombre desde la invención de la bomba atómica está en condiciones de conseguir su propia aniquilación. Esto le convierte en una especie de Prometeo y en un dios de la aniquilación (un Dios, que ciertamente no puede crear nada de la nada, pero es completamente capaz de hacer que todo se destruya). 
mucho más importante el nihilismo existencial, tal y como se expresa en la «tradición del romanticismo enemiga y hermanada con el idealismo». «Aquí dominan ya las experiencias del subjetivismo considerado melancólico, la vivencia de la soledad y la impotencia, del aburrimiento y hastío vital, de la disolución "irónica" y lúdica de la seriedad de la vida» (Ottmann 1999: 330). En el nihilismo político del siglo XIX, cuya representación insuperable la ha conseguido Dostoievski en su novela Los Demonios (1873), cambia la melancolía y la desesperación románticas por la ira. Aquí se impone una voluntad de destrucción radical. El mundo aparece como un valor (es decir, bastante desvalorizado) que tiene que sucumbir.

Henning Ottmann hace un balance de esto diciendo que Nietzsche se ha lavado con las aguas de todas las tradiciones [nihilistas]:

La fuerza de la "aniquilación" que va del poder de Dios al poder del sujeto es para él la consecuencia de la "muerte de Dios" como de la conciencia moderna. Él está al final de la tradición idealista, que disuelve un neokantismo escéptico y radical. Con el romanticismo participa de las experiencias existenciales, que revelaban en el nihilismo de los años ochenta una nueva cualidad de la desesperación y de la desintegración [...]. El nihilismo político le llegó de escritores, que, como Turgeniev, se fundaron a su vez en la tradición del hegelianismo ruso o, como Dostoievski, que quería exponer la unión de la "muerte de Dios" con el inmoralismo, la destrucción y la autodestrucción» (Ibid.: 331)

Por eso, no sorprende que la comprensión de Nietzsche del nihilismo sea especialmente rica. Él ha analizado, como ningún pensador antes que él, el complejo mundo fenoménico unido con el nihilismo y ha puesto de relieve la importancia filosófica, psicológica y cultural del nihilismo. Además él ha contado la historia del nihilismo, que la describe como un proceso que impregna profundamente toda la cultura occidental. El nihilismo como proceso comienza su carrera, según Nietzsche, como optimismo socrático, que se entrega al progreso como a un dios y se presenta con la pretensión de «corregir» el mundo lleno de errores, es decir, el mundo que se experimenta erróneo de un día (que puede llegar pronto). Realmente, el socratismo cree - sobre todo el moderno - «en una corrección del mundo por medio del saber» (GT 17, OC I 408, KSA 1, 115). Según Nietzsche esta fe no lleva a ninguna otra parte más que a la catástrofe, puesto que el mundo en su mayor profundidad es caótico y con ello es una pieza decisiva lejos de resistir a la corrección y el mejoramiento. Como un veneno subrepticio el nihilismo, según Nietzsche, también entrevera al Cristianismo. En primer lugar, «la hipótesis cristiana de la moral» parece haber sido justamente el mejor medio contra el nihilismo, «pues prevenía que el hombre se despreciara como hombre, que tomara partido contra la vida, que desesperara del conocer». Dios otorga al 
hombre mortal, y en este sentido caduco, «un valor» absoluto, garantiza un sentido de la vida, promete «un conocimiento adecuado» (1886, 5[71], FP IV 164, KSA 12 211) especialmente en las cuestiones morales y ofrece al hombre estabilidad y orientación. Dios es, con otras palabras, el bálsamo último para un ser finito, que como tal, por decirlo así, vive siempre y eternamente dentro de relaciones ontológicamente precarias. Pero la duración del citado remedio está limitada. Peor aún, la semilla de la maldad habita dentro de él mismo. Es la voluntad de verdad educada a través del cristianismo, la que se aplica finalmente como voluntad crítica contra el mismo cristianismo, en la medida en que Dios como «una hipótesis demasiado extrema» (Ibid.: 212) se encasilla y, como consecuencia, baja de categoría a una forma de fábula. Entre tanto, los hombres se han acostumbrado de una manera fatal a una vida con seguridad metafísica, a un mundo y una vida con red y doble piso (tras el más acá nos espera algo mejor en el más allá14) y a una existencia cuya significatividad parece garantizada. Una vida con un sentido reducido ya no parece ser suficiente frente a este presagio. Como consecuencia de la erosión de la fe en Dios se despliega, según Nietzsche, una desconfianza fundamental contra todo posible sentido y toda presupuesta finalidad de la vida. Se trata ahora de la sospecha de qué valores y fines podían ser en verdad nada más que un mero cebo para la continuación de una existencia en sí sin sentido, como dice Nietzsche, «con los cuales la comedia se prolonga sin acercarse sin embargo de ninguna manera a un desenlace» (Ibid.: 165). El hombre en la época del nihilismo es un ser seducido, que ya no cree en la fuerza donadora de vida del cebo, pero sin embargo sigue necesitando infelizmente un señuelo. Así, él entiende entonces, que «uno está siendo burlado y sin embargo no tiene el poder de no dejarse burlar» (Ibid.). Bajo el nuevo signo de la ausencia de Dios todo parece ser en vano para el hombre acostumbrado al sentido, pues «las posiciones extremas no son sustituidas por posiciones moderadas sino por posiciones otra vez extremas, pero inversas»; la nihilista "creencia en la absoluta inmoralidad de la naturaleza, en la falta de finalidad y de sentido», es sin embargo «el afecto psicológicamente necesario» que entra «cuando ya no se puede sostener la creencia en Dios y en un orden esencialmente moral.» (Ibid, 165) No está claro del todo, que no pueda ya dar ningún sentido existencial - y Nietzsche con el superhombre da también un nuevo «sentido a la tierra» (cf. Z I prólogo 3, OC IV 73, KSA 4, 14f.) -, solo porque se desmorona una interpretación de la vida y de su finalidad; «la interpretación parece como si no hubiera absolutamente ningún sentido en la existencia,

14 La introducción de un segundo mundo inteligible, que es valorado prioritariamente ontológica y moralmente (eterno y justo), la entiende Nietzsche como un acto nihilista, en la medida en que la realidad empírica aparece solo como un estadio transitorio inferior. 
como si todo fuera en vano» (FP IV 165,1 886, KSA 12 5[71], 212). Por tanto, con la muerte de Dios el nihilismo alcanza un punto álgido provisional. Él, que hasta el momento se propagó de una manera sublime y subcutánea en el socratismo y el cristianismo, se manifiesta ahora en la superficie. En cuanto a la historia y con ellos a un lado de la duplicidad causante del nihilismo. Paso ahora a explicar el segundo lado de dicha duplicidad; la mismidad.

\section{2 LA DIMENSIÓN ANTROPOLÓGICA DEL NIHILISMO}

Desde la perspectiva antropológica, el nihilismo pertenece en cierta manera a la dotación fundamental del hombre. El hombre es un ser esencial que se relaciona consigo mismo. Para la actividad principal del hombre cuenta su actividad de orientación dentro del mundo, con lo cual corresponde a la capacidad de juzgar un lugar preferente en el repertorio de sus instrumentos de orientación. Ahora se muestran nihilistas al fijarse con más exactitud ante todo como los que condenan: «Un nihilista es el hombre que, respecto del mundo tal como es, juzga que no debería ser, y, respecto del mundo tal como debería ser, juzga que no existe. En consecuencia, existir (actuar, sufrir, querer, sentir) no tiene sentido» (FP IV 250, 1887, 9 [60], KSA 12, 366). Partiendo de esta definición de la posición nihilista se pone de manifiesto la estrecha conexión que se da entre el juicio del mundo y el del yo. La existencia del yo tampoco tiene sentido en un mundo que se desecha. En general me parece que desde una perspectiva antropológica el autojuicio negativo es el núcleo fuerte del nihilismo. Por consiguiente, me gustaría enriquecer «la frase del nihilismo» antes citada con el siguiente complemento: Un nihilista es el hombre, que juzga sobre sí mismo, cómo es él, cómo no debería ser, y juzga sobre sí mismo cómo debería ser, juzga que no existe. Naturalmente, ambas proposiciones del nihilismo alcanzan una irresistible eficacia solo si se abandona también la esperanza sobre un cambio para mejorar las condiciones del mundo, es decir del yo.

Como a un ser que juzga y se relaciona consigo mismo el nihilismo está grabado en el hombre como una posibilidad radical y negativa del comportamiento consigo mismo. Si el hombre usa realmente también esta posibilidad exigente, depende de nuevo también de condiciones externas. Hay circunstancias que hacen más probable la autoelección nihilista, y aquellas que la hacen más desacertada. De este modo, el nihilismo como hecho antropológico y el nihilismo como fenómeno cultural están relacionados estrechamente uno con otro. 


\section{II.3 AGRESIÓN Y RESIGNACIÓN: DE LAS FORMAS ACTIVAS Y PASIVAS DEL NIHILISMO}

Después de que hayan sido aclarados el origen y la esencia del nihilismo mediante una mirada a su duplicidad causal, no resulta difícil comprender, en qué medida el nihilismo, el «más inquietante de todos los huéspedes», es extraño, es decir, amenazante. La autonegación y/o la negación del mundo unida al nihilismo pueden manifestarse, por eso, de muy diversas formas. Fundamentalmente se pueden concebir, primero los modos de relación nihilistas activo-destructivo, y en segundo lugar pasivo-autodesctructivos.

1. Los nihilistas del tipo activo - hablo en lo sucesivo de nihilistas activos para simplificar e idealizar el tipo - son destructores. Es cierto que en ocasiones se encuentran en situación de aportar una fuerza poderosa, desplegarla, sin embargo, no de modo productivo (cf. FP IV 242, 1887, KSA 12, 9[35], 351). Esto se debe a que ellos sacan su fuerza de una fuente negativa, del resentimiento y desesperación, es decir, del nihilismo. «El nihilismo activo - dice Gillespie $(1995,180)$ es en definitiva una manifestación no de alegría y superabundancia, sino de negación y desesperación». En aras de un futuro mejor la destrucción puede ser necesaria en casos extremos. Sin embargo, los nihilistas activos son solo un azote para el presente. A través de su obrar no apoyan de ningún modo un futuro mejor. Para ello les falta el espíritu afirmativo. Quien no quiere afirmarse a sí mismo ni al mundo, tampoco se detiene ante la destrucción del otro. (cf. Ibid.: 181).

2. Los nihilistas de tipo pasivo - hablo en lo sucesivo de nihilistas pasivos para simplificar e idealizar el tipo - son autodestructivos. Mientras que la actividad del nihilismo activo se puede comprender mejor como una forma de sobreexcitación, como una forma de vigilia agresiva, la pasividad del nihilismo pasivo, al contrario, parece ser una especie de cansancio, más exactamente aún: una forma de cansancio resignado (cf. FP IV 242, 1887, KSA 12, 9 [35], 351). El nihilismo pasivo, que siente el estado del mundo como insoportable, elige la retirada al interior, se instala abandonando el mundo tras los muros protectores de su catillo interior. Él está cansado del mundo. En la medida en que el nihilista pasivo siente como insoportable no solo el mundo, sino también su yo, es decir, a sí mismo, por lo mismo se encontrará también incómodo en su fortaleza interior. Sin embargo él no reúne la fuerza para exteriorizar su autonegación, como corresponde a la estrategia del nihilista activo. No es raro que el nihilismo pasivo se exteriorice como depresión y melancolía.

\section{4 ¿SUPERACIÓN DEL NIHILISMO?}

Nietzsche ha experimentado la exageración del nihilismo activo tanto en 
su propio cuerpo como el cansancio resignado del nihilismo pasivo. Entretanto, en cierto modo cree en un más allá del nihilismo cuando afirma ser: «el primer nihilista perfecto de Europa, el cual, sin embargo, en él ha vivido ya el nihilismo mismo hasta el final - el cual lo tiene tras él, bajo él, fuera de él...» (FP IV 489 NL 1887, KSA 13, 11[411], 190). La corrección de esta autovaloración de sí mismo puede ser puesta en duda en tanto que el nihilismo tomado en sentido estricto es una posibilidad dada continuamente de un ser autoreflexivo y que juzga; a este respecto, un hombre nunca puede realmente tener el nihilismo detrás, debajo y fuera de sí, sino que lo soporta continuamente en sí al menos como un peligro latente. En este sentido no hay ninguna superación del nihilismo. Sin embargo, se puede rechazar - no una vez por todas, pero si una y otra vez. Una ojeada a las estrategias de Nietzsche, de rechazar el nihilismo y ponerlo en su lugar, muestra que para él esto tiene que ver principalmente con debilitar el juicio negativo del mundo y del valor. La preocupación más acuciante de Nietzsche es consecuentemente la de mantener, es decir, impedir que el nihilismo irrumpa a la superficie. Ahí ve Nietzsche, ante todo en la matriz moral del Occidente acuñada cristianamente, el terreno abonado para los juicios negativos del yo y del mundo, y considera como algo necesario una transvaloración de los valores. Su filosofía crítica con la cultura y la moral ${ }^{15}$ tiene como meta, por lo tanto, un programa de transvaloración antinihilista. Los viejos ideales deben ser abolidos, porque están contaminados nihilisticamente; por lo demás, su lado nihilista está siempre abierto: «Todo el idealismo de la humanidad anterior está a punto de convertirse en nihilismo [...]» (FP IV 221,1886, KSA 12, 7[54], 313). Apenas es imaginable, que el hombre pueda vivir completamente sin ideales ni tablas de valores. Son necesarios por lo tanto nuevos valores que se destaquen por no estar impregnados de nuevo de modo nihilista. Ante todo, estos valores no deben volver a servirse de una más allá, al que considera como un valor supremo, (y a los ojos de Nietzsche no es más que una mera fantasía) frente al más acá, tal y como sucede paradigmáticamente según Nietzsche en el platonismo y Cristianismo. Tampoco deben estos valores, y para Nietzsche este es el problema central del cristianismo, reprimir «todas las naturalezas que afirman la vida de una manera poderosa y con voluntad firme» (Gerhardt 1999: 156), en tanto que condenan las manifestaciones de los fuertes como inmorales o incluso como pecaminosas, mientras que idealizan a los débiles. De este modo, no solo se hace propiamente hombres fuertes a los

15 También sería posible, como indica van Tongeren 2016a, 124, subsumir la crítica de la moral bajo la crítica de la cultura. Puesto que Nietzsche utiliza especialmente tanta ponderación sobre la moral occidental, me parece justificado identificar por separado la crítica de la moral, para acentuar su estatus especial. 
neuróticos de la voluntad ${ }^{16}$, sino que se «debilita a los hombres» por lo general y «le obliga a una determinación esencial indigna» (Möbuß 2015, 247).

Como fuerza fundamental enemiga de la vida y francamente esquizofrénica de la moral acuñada por el cristianismo Nietzsche estipula una voluntad de nada, cuya arma poderosa es la devaluación de todo aquello que busca poder y grandeza. La transvaloración de Nietzsche se aplica por tanto contra un canon de valores, cuyo autor anónimo, por decirlo así, es la voluntad de nada (porque normalmente es irreconocible y eo ipso desconocido). El Nietzsche tardío pone en lugar de la voluntad de nada la voluntad de poder.

¿Pero la transvaloración de los valores es realmente un concepto convincente, con cuya ayuda, el hombre nacido dentro de un mundo de valores dictado por la voluntad de nada encuentra un camino desde el nihilismo?¿Pues no es así, que un ideal - es decir por tanto también un nuevo valor que se convierte en poder a través del proceso de transvaloración -, independiente de su forma material correspondiente, siempre contrastan ${ }^{17}$ un ser-estado con un sería-estado y con ello permiten el avance de autocondena nihilista? Creo que Nietzsche es consciente de este problema, cuando en La gaya ciencia reflexiona sobre el papel del hombre como «principio 'negador del mundo', el hombre como medida del valor de las cosas, como juez del mundo, que por último pone a la existencia misma en el platillo de la balanza y la encuentra demasiado ligera» (FW 346, OC III 862, KSA 3, 580) y sobre las generaciones de los hombres del futuro, que a consecuencia del nihilismo han contribuido al escepticismo frente a todos los valores, y que se encuentran ante una «terrible alternativa»: «io bien suprimís vuestras veneraciones o bien - a vosotros mismos» (Ibid.: 581). Este o/o es terrible, porque no parece tener una auténtica alternativa, sino que

16 Por neuróticos de la voluntad entiendo, de acuerdo con Otto Rank, alguien que no puede querer «sin tener un sentimiento de culpabilidad a causa del querer» (Rank 1929, 106). (Sobre la «neurosis del querer» ver Brock 2015, 228-230).

17 Nietzsche define como tarea central de los filósofos del futuro, cuya llegada evoca literalmente ante todo en Más allá del bien y del mal, la creación de los valores. Mientras él considera a filósofos como Kant y Hegel solo como trabajadores filosóficos cuya actividad consiste en que «establecieron y redujeron a fórmulas algunos grandes hechos relativos a las estimaciones de valor - es decir, antiguas fijaciones de valor, creaciones de valor que han sido predominantes y durante un tiempo se las ha llamado "verdades"» (JGB 211, OC IV 377 KSA 5, 144), considera él como «auténticos filósofos» a aquellos que «mandan y legislan; ellos dicen "¡así debe ser!"», los cuales determinan de qué manera «primero el hacia dónde» y el «para qué» (Ibid. 378). En la enfática afirmación del que ha de venir yace al mismo tiempo la posibilidad de la negación tan enfática de lo existente. El peligro de la autodesvalorización nihilista no se deja conjurar tan fácilmente. Del problema de cómo se afirma el futuro sin desechar lo existente en bloque, es decir, sin despreciarlo, se ocupa ya Nietzsche en Schopenhauer como educador, y más tarde de nuevo en Así habló Zaratustra. La idea de Nietzsche, de que el problema debe tener solución, consiste en una especie de humillación productiva, es decir, una vergüenza frente a la situación actual, que sin embargo no deriva en resentimiento, porque su carácter negativo es mitigado por la mirada que mira hacia adelante y, si se quiere, es transfigurado. El problema lo he tratado en otro lugar más ampliamente. (cf. Brock 2015, 343 y Brock 2018, 192-194). 
más bien designa un conflicto trágico, que como tal no deja ninguna decisión «correcta», a través de la cual fuera a solucionarse un problema existente o a evitarse un peligro amenazante. Con el terrible o/o ocurre como con la elección proverbial entre peste y cólera: «Lo último [suprimirse a uno mismo] sería el nihilismo; ¿pero lo primero [supresión de las veneraciones] no sería también - el nihilismo?- Éste es nuestro signo de interrogación» (Ibid.) ${ }^{18}$ Ante este trasfondo es lógico que Nietzsche lleve su lucha con el nihilismo no solo al amplio campo de la crítica de la cultura y de la moral, en donde tienen lugar, por decirlo así, grandes movimientos de tropas, sino que se atreve también con el más pequeño frente (sin embargo más sutil y filosóficamente no menos relevante) de las relaciones humanas con el mundo y consigo mismo. Cuando Nietzsche en los nuevos prólogos (1886) de las dos ediciones correspondientes de Humano demasiado humano y de La gaya ciencia reflexiona sobre un «arte de la transfiguración» (FW prólogo 3, OC III 719) y sobre la «gran salud» (MA prólogo 4, OC III 72) que conlleva, retoma el programa temprano de la justificación estética de su libro de la tragedia (1872), pero le da, por así decirlo, un giro filosófico existencial, en la media en que se dirige explícitamente al singular como un potencial transfigurador de su propia existencia individual.

\section{LA REFUTACIÓN DEL NIHILISMO: EL ARTE DE NiETZSCHE DE LA TRANSFIGURACIÓN}

El núcleo antinihilista del arte de la transfiguración consiste en iluminar la propia vida, en cuyo resplandor parece absurdo el juicio nihilista más sombrío sobre la vida. Por eso, es también el punto decisivo del programa de la justificación estética de la existencia de El nacimiento de la tragedia. La tragedia griega - la obra de arte por excelencia- es descrita allí como una especie de referencia de transfiguración reconocida generalmente, que indica al visitante, es decir, al espectador un modo determinado de visión de la vida (encarnada como tipo ideal de vida mediante el coro de sátiros), mediante la cual incluso lo horrible aparece como bello. Este punto de vista de lo terrible es posible, porque la tragedia ofrece un «consuelo metafísico», que se dirige al individuo, cuyo potencial consuelo se despliega entonces, cuando el individuo abstrae de su propia individualidad y se comprende como parte de un todo vivo universal que late. «Y el efecto más inmediato de la tragedia dionisíaca es

18 Sin embargo, Nietzsche formula su terrible alternativa como un signo de interrogación. Sugiere que se trata de una elección entre la peste y el cólera, una elección, de la que se arrepentirá inevitablemente de las dos (Kierkegaard lleva esto formalmente hasta el punto de que «te cases o no te cases, tú te arrepentirás de las dos cosas [...]»), pero no excluye que se abrirá probablemente todavía una salida feliz a esta situación dilemática. Quizás no sea demasiado decir, si se reconoce en el intento de buscar este camino la motivación central de la filosofía de Nietzsche (al menos a partir de La gaya ciencia.) 
que el Estado y la sociedad, los abismos en definitiva entre los seres humanos, retroceden ante un sentimiento de unidad que tiene fuerza superior, el cual lleva de retorno al corazón de la naturaleza. El consuelo metafísico - con el cual [...], en el fondo de las cosas, y pese a todo el cambio de los fenómenos, la vida es indestructiblemente poderosa y placentera, ${ }^{19}$ ese consuelo aparece con corpórea claridad como coro de sátiros [...]». (GT 7, OC I 362, KSA 1, 56). De este modo, el «coro de sátiros» se convierte en el «acto salvador del arte griego», y ciertamente, para ser exacto, en aquello que salva la vida, en la medida en que la tragedia no enmascara precisamente el sufrimiento, que pertenece a la vida, la finitud y el dolor de la existencia ${ }^{20}$, sino más bien a «esos pensamientos de náusea sobre lo horroroso o absurdo de la existencia convirtiéndolos en representaciones con las que se puede vivir» (Ibid.: 363). Por lo tanto, a la luz de la tragedia, es decir, desde su perspectiva, la vida se transfigura. Sin embargo, con Eurípides, por desgracia, se produce una transformación de la tragedia, que va en detrimento de la transfiguración. A través de Eurípides, al que Nietzsche antes lo consideraba un pensador y un poeta (cf. GT 12, OC I 383, KSA 1, 80) y, además, como un cómplice furtivo de Sócrates, la tragedia que embellece la existencia prospera precisamente en manos del socratismo nihilista. Un nuevo «espíritu no-dionisíaco» (GT 17, OC I 407, KSA 1, 114) toma posesión de ella. Este espíritu corroe y «combate» desde dentro «la sabiduría y el arte dionisíacos», en la medida en que «intenta disolver el mito». El libro de la tragedia de Nietzsche informa no solo de El Nacimiento de la tragedia desde el espíritu de la música, sino también de la muerte de la tragedia, «desde el espíritu de lo no-dionisiaco» (Ibid.: 407). La tragedia pierde su fuerza especial a consecuencia de la racionalización y moralización. Pierde su característica central, justificar estéticamente la existencia y el mundo. Si tenemos esto en cuenta, entonces se comprende que la muerte de la tragedia para Nietzsche es como la muerte de Dios, un acontecimiento decisivo para la historia del nihilismo europeo Pues

19 Y en un pasaje posterior: «[...]bajo el torbellino de los fenómenos, la vida eterna continúa fluyendo [...]» (GT 18, OC I 409, KSA 1, 115).

20 Paul von Tongeren pone el énfasis también en este punto: «Como hemos visto [...] en el ejemplo de la tragedia, el arte alcanza la realización de la existencia [von Tongeren se refiere aquí a FP IV 1887-1888, KSA 13, donde la afirmación y la «realización de la existencia» son definidas como características del arte; Eike Brock], por el hecho de que él no oculta lo terrible o lo relativiza desde un punto de vista ideal, sino que el arte posibilita una segunda mirada, por la que este momento aparece como bello» (Von Tongeren 2016a, 122). De esta manera la tragedia abre al espectador la posibilidad de transformarse en el fondo en un artista, un artista del ver específico, es decir, del mirar, que transforma de nuevo las cosas contemplándolas. Este arte de la transformación a través del ver es un arte del embellecimiento: «El arte consiste en ver lo feo como bello, no porque uno se engañe, sino porque uno se convierte primero en espectador, aprende a disfrutarlo como drama y se transforma de ese modo en el artista que hace bellas las cosas» (Ibid.) 
a diferencia de la Grecia clásica la moderna no dispone ya de una obra de arte transfiguradora, que ejerza en la vida social el estatus de una institución y con ello ejercite de esa forma una fuerza determinante en el conjunto de la sociedad. Nietzsche no dirige en última instancia su atención a este fundamento ${ }^{21}$, a la muerte lenta, es decir, a la pérdida de la tragedia, sino a las cuestiones relativas al potencial artístico del individuo, es decir, al hombre como poeta de su propia vida (cf. FW 299, OC II 839, KSA 3, 538).

\section{III.1 EL MUNDO ES NUESTRA REPRESENTACIÓN, NUESTRA ESCENOGRAFÍA Y NUESTRA PANTALLA}

Nietzsche asume las ideas principales de la teoría del conocimiento de Schopenhauer, con su «principio fundamental» (WWV 1, § 1), según el cual el mundo es nuestra representación, si bien con la palabra «representación» no piensa tanto en un fenómeno ${ }^{22}$ como en una representación teatral ${ }^{23}$. El mundo como representación es, visto así, como un teatro del mundo ${ }^{24}$. En este teatro nosotros no tenemos, sin embargo, un papel pasivo: "estamos puestos nosotros no primariamente en el papel pasivo como "espectador y oyente" ante el gran espectáculo visual y sonoro que es la vida», sino que cada uno de nosotros es «él mismo también el auténtico poeta de la vida y quien la prolonga poéticamente» (FW 301, OC III 840, KSA 3, 540). Esto es algo que tiene su importancia. Nietzsche se queja, de que precisamente incluso los espíritus contemplativos, que realmente se caracterizan ante otros por una especial agudeza visual del mundo, pasan por alto regularmente su papel

21 A esto se añade al menos también la esperanza fallida de ejercer la ópera de Wagner en un futuro una función social semejante a como la tuvo la tragedia griega para la Grecia clásica, así como la mirada autocrítica sobre su libro de la tragedia considerado más tarde por el mismo autor como metafísica.

22 Cf. Schopenhauer WWV 1, § 1: «"El mundo es mi representación”: esa es la verdad que vale para todo ser viviente y cognoscente, aunque solo el hombre puede llevarla a la conciencia reflexiva abstracta [...] Entonces le resulta claro y cierto que no conoce ningún sol ni ninguna tierra, sino solamente un ojo que ve el sol, una mano que siente la tierra; que el mundo que le rodea no existe más que como representación, es decir, solo en relación con otro ser, el representante, que es él mismo[...] Ninguna verdad es, pues, más cierta [...] que esta, que todo lo que existe para el conocimiento, o sea, todo este mundo es solo objeto en referencia a un sujeto, intuición de alguien que intuye; en una palabra, representación».

23 Realmente Schopenhauer también piensa el mundo como representación en este doble sentido, como lo muestra Lerchner 2013

24 Un Theatrum mundi es el mundo en Nietzcche naturalmente, pero no en cuanto que en el teatro del mundo de Nietzsche no hay ningún dios que lo dirija. 
activo en el mundo - un papel, en el que en cierto modo se trata nada menos que de la creación del mundo:

Nosotros, los pensantes-sintientes, somos los que hacemos real y continuamente algo que aún no existe: todo el mundo, en eterno crecimiento, de estimaciones, colores, pesos, perspectivas, escalas, afirmaciones y negaciones. [...] Lo que en el mundo actual tiene valor no lo tiene en sí, por su naturaleza - la naturaleza carece siempre de valor: - sino que en un momento se le ha dado, donado un valor, y ¡hemos sido nosotros los dadores, los donantes! ¡Sólo nosotros hemos creado el mundo que incumbe en algo al hombre! (Ibid.)

El mundo como representación es, según esto, el escenario y la tramoya sobre el que no solo actuamos, sino en el que también construimos continuamente. Nosotros somos actores y escenógrafos al mismo tiempo; caminamos en la primera línea, mientras damos forma al trasfondo. Como pensantes-sintientes (ver supra), tomamos el mundo que nos rodea, con sus colores, sabores y olores no simplemente como verdadero, sino que al mismo tiempo los moldeamos. Nuestra fuerza de modelación depende, sin embargo, del «material», del entorno y del estado de ánimo que nosotros tengamos. Nosotros no creamos ni moldeamos algo de la nada. Estamos más bien situados siempre en un mundo, que en distintos momentos históricos permite y sugiere distintas posibilidades del mundo, es decir, de la forma de decorado. Además hay acontecimientos que de manera especial desafían a los hombres como artistas que forman el mundo. La muerte de Dios es un acontecimiento semejante. Si se hunde concretamente la idea de Dios, si se agota su fuerza irradiadora, entonces aparece el mundo con otra luz distinta: «¡La iluminación y los colores de todas las cosas han cambiado! [...] Todas las vivencias brillan de otro modo, porque un dios resplandecía desde ellas[...]» (FW 152, OC III 811 KSA 3, 495). Con la muerte de Dios acontece con el mundo como representación la «más grande transformación» (Ibid.). Consiste en que después de la muerte de Dios y de la volatilización de las ideas religiosas por lo general todo aparece en tonos de colores distintos. El mundo ya no alumbra reflejando una llama numinosa, sino últimamente brilla con una especie de luz secular. Esta transformación fundamental de la elación de la luz y del cambio de color de las cosas asociados con ello no debe por eso ser considerada en todos los aspectos como algo catastrófico. Realmente la nueva luz ilumina algunos rincones del mundo de una manera mucho más clara que la antigua, así por ejemplo cuando se trata del «territorio infernal» de la existencia, de la angustia ante el castigo divino y autodesprecio del pecador ${ }^{25}$ : «Toda injusticia tenía un

25 Cf. Sobre este tema ver también el discurso secular edificante de Zaratustra al funámbulo que se está muriendo y que se horroriza ante las puertas del infierno, en Así habló Zaratustra: «Po mi 
efecto diferente sobre el sentimiento: porque se temía una represalia divina, y no solo una pena y una deshonra civil. ¡Qué era la alegría en una época en la que se creía en diablos y tentadores! ¡Qué la pasión cuando se veía acechar de cerca a los demonios! ¡Qué la filosofía cuando la duda era sentida como un pecado del tipo más peligroso, como una profanación del amor eterno, como desconfianza frente a todo lo que era bueno, elevado, puro, misericordioso!». Sin embargo, en general, el mundo después de la muerte de Dios aparece - al menos temporalmente - menos llamativo que antes: «Hemos dado a las cosas un color nuevo, seguimos pintándolas sin cesar, - ¡pero qué podemos hacer mientras tanto frente a la riqueza de colores de aquella antigua maestra! - me refiero a la humanidad antigua» (Ibid.). La «antigua maestra» pintaba de alguna manera como bajo los efectos de las drogas; ella movió el pincel inspirada en una fe todavía viva en dios y los dioses. Frente a eso la «nueva» humanidad está desencantada. La paleta de colores que está a su disposición cuando colorea el mundo, parece a primera vista más pobre que antes; el tono de los colores ya no muestra la misma intensidad. Las explicaciones de Nietzsche para la más grande transformación (FW 152) demuestran, que el mayor desafío ante el que se encuentra la humanidad después de la muerte de Dios es de una naturaleza no solo moral ${ }^{26}$ o psicológia ${ }^{27}$, sino necesariamente también estético-existencial. La pregunta que surge de nuevo es, cómo puede lograrlo en el futuro, atribuir al mundo una profundidad y anchura cromática adecuada (es decir que posibilite la existencia, transfigurativamente), si al dibujar uno ya no puede confiar en la misma fuerza irradiadora de los colores, como lo

honor amigo mío, respondió Zaratustra, que no hay nada de eso de lo que habas: no hay ni demonio ni infierno. Tu alma estará muerta antes que cuerpo: ¡así que no temas ya nada!». Parece simple el asunto tal y como se representa abiertamente Zaratustra la muerte después de la muerte de Dios, pero no - en todo caso no para el funámbulo. En el ejemplo del funámbulo se puede observar cómo una angustia deja paso a otra, cuando ella cede: En lugar de la angustia ante el demonio y el infierno, es decir, ante los tormentos del alma entran el horror vacui y la desesperación nihilista, todo en la vida, es decir, toda la vida podría haber sido en vano, como formas de juego del nihilismo: «El hombre lo miró con desconfianza: "Si dices la verdad, dijo entonces, no pierdo nada si pierdo la vida. No soy más que un animal al que han enseñado bailar por medio de golpes y poca comida"». Ciertamente, Zaratustra intenta contrarrestar el desprecio de sí mismo del funámbulo (lo que considero como núcleo del nihilismo), mientas que él le honra por su vida peligrosa, en la medida en que le promete que lo enterrará con sus propias manos. La escena muestra, sin embargo, aunque el funámbulo finalmente parece estar agradecido, lo difícil que es soportar la finitud bajo la condición de la muerte de Dios.

26 Pensemos un momento en el principio nihilista de los asesinos: «Nada es verdad, todo está permitido» (Cf. Apartado 1). Ver también Vattimo 2004, 22: frente a la muerte de Dios piensa que, «la fe en Dios era un factor poderoso de la racionalización y de la disciplina que le ha permitido al hombre salir de la selva del bellium omnium contra omnes».

27 El nihilismo después de la muerte de Dios se manifiesta psicológicamente también de modo especial como sentimiento de un profundo abandono: «La necesidad profunda del hombre, de no sentirse en el mundo solo y abandonado, anteriormente ha sido satisfecha por la idea de que hay un Dios que ha creado el mundo y se preocupa de cada una de la criaturas» (Fromm 2017, 49). 
permitían todavía en tiempos pasados. Una respuesta de Nietzsche a esta cuestión existencial se debe a la visión de que la calidad del color en realidad no depende de los colores mismos, sino del artista que los aplica. El brillo de los colores antiguos se debe por eso a un ingrediente especial del pintor, que se puede obtener de nuevo solo en determinadas circunstancias. Pues, colores, que están en condiciones de sumergir el mundo en una luz divina, se lo deben incluso a contextos de transfiguración, en la media en que se originan en circunstancias teomaníacas. Sin embargo, si Dios ha muerto, el hombre debe encontrar un camino, los colores, y eso quiere decir en definitiva: conferir también al mundo un hechizo transfigurador sin inspiración teomaníaca. Pero este camino es el arte de la transfiguración.

\section{III.2 DEL DECIR SÍ Y DEL HACERLO BELLO: EL ARTE DE LA TRANSFIGURACIÓN}

Hasta ahora se ha hablado mucho de la transfiguración. Sin embargo ¿qué tiene que ver propiamente el arte de la transfiguración con el arte? ¿De qué clase de arte se trata exactamente? ¿Es la expresión «arte» en general la denominación correcta para el programa de transfiguración existencial de Nietzsche? Realmente no es sencillo conceptuar filosóficamente el arte de la transfiguración. Un primer intento de Nietzsche de justificar el mundo por la transfiguración se convierte en un problema menor desde el punto de vista teórico. También aquí, en el libro de la tragedia, todo depende del arte, pues con la tragedia griega se refiere a una obra de arte específica que se comprende relativamente con claridad en sus propiedades constitutivas de género, la cual considerada estéticamente efectiva tiene una importancia supraindividual, en tanto que desempeña, por así decirlo, como un lugar de experiencias de una transfiguración colectiva. La transfiguración, de la que trata Nietzsche en $E l$ nacimiento de la tragedia, es por tanto el fruto de una (por lo demás nacida desde el sufrimiento) obra de arte, que está en disposición de transmitir una experiencia transfiguradora. «La tragedia reproduce en forma artística la experiencia original extático-religiosa del ritual orgiástico dionisíaco» (Ugolini 2000: 338). De esta manera, el primer libro de Nietzsche no trata propiamente del arte de la transfiguración, sino más bien del arte transfigurativo. Cuanto más intensamente concentra Nietzsche sus reflexiones filosóficas sobre el hombre singular después de El nacimiento de la tragedia, tanto más pone en el punto focal su capacidad transfigurativa, es decir, el hombre como artista potencial de la transfiguración. Dentro de la filosofía de Nietzsche de la afirmación se lleva a cabo por tanto un movimiento del arte transfigurativo en dirección al arte de la transfiguración. Pero Nietzsche no abandona el terreno filosófico de los antiguos. Pues el arte de la transfiguración se puede entender 
de la mejor manera como arte antinihilístico de la vida ${ }^{28}$. Objeto de este arte de la vida no es la vida como tal, sino la vida del hombre singular. La necesidad de transfiguración de la vida no obliga de igual manera por eso a cada hombre y tampoco en cada momento de la vida individual. Nietzsche naturalmente sabe eso con exactitud y no sorprende por tanto que trate el tema del arte de la transfiguración en el contexto de su historia clínica personal. Además, Nietzsche habla de su enfermedad y del sufrimiento que conlleva en el prólogo a la segunda edición de La gaya ciencia desde la perspectiva de un convaleciente, que recuerda que él ha escrito el libro como un convaleciente ${ }^{29}$. A primera vista parece difícil sacar de una enfermedad algo de lo que alegrarse. La convalecencia, que sin duda pertenece al decurso de una enfermedad (en cuanto que se trata de una evolución feliz), ha de ofrecer entre tanto el cese del dolor y la lenta recuperación de la fuerza y vitalidad. Y eso no es poco. De esta manera, en cada enfermedad que se supera, está el triunfo y la alegría de la salud, que el sano, es decir, el que no está afectado por una enfermedad, a menudo le gusta dar por supuesto ${ }^{30}$. Nietzsche en cambio interpreta La gaya ciencia - el libro en cuyo centro salta a la vista la muerte de Dios como un «acontecimiento enorme» (FW 125, OC III 802 KSA 3, 581) ${ }^{31}$, a través del

28 Cf. Brock 2014. Para una filosofía del arte de la vida según el modelo antiguo Ernst (2016, 302-307) indica cuatro observaciones características: 1) la prioridad de la praxis sobre la teoría, lo cual sin embargo 2) no debe llevarnos a una minusvaloración de la teoría. La teoría es más bien valorada y cultivada como base para una praxis filosófica mejor. 3) Además, la filosofía debe ser practicada integralmente y en definitiva la filosofía fue concebida como arte de la vida incluso como arte, es decir, como techne, que uno puede y debe ejercer. Como auténtica meta de la filosofía invita sin embargo a una mejor vida. Como veremos, encontraremos todos esos puntos unas veces de una manera más exacta y otras menos en el arte de la transfiguración de Nietzsche. En todo caso, prevalece un acuerdo tan unánime que también mirando a la historia de la filosofía se puede calificar justamente como una filosofía del arte de la vida.

29 Un tema, al que Nietzsche dedica también alguna atención en Así habló Zaratustra. (Cf. Z III «El convaleciente»).

30 Salud y enfermedad son a su vez no solo temas de medicina sino también filosóficos. Solo el intento de definir la esencia de la enfermedad y la salud demuestra que se implican mutuamente. ¿Es la salud una ausencia de enfermedad o se trata por el contrario de un estado, o mejor de una capacidad? (Así lo propone Whitbeck 2012, 208, concebir la salud «como una capacidad psicofisiológica de reaccionar adecuadamente en situaciones diversas»). Como es sabido, Nietzsche se inclina por esta última concepción. Su concepto de la salud es dialéctico, en cuanto que parte de que la salud solo se acredita ante la enfermedad. «Salud» en el sentido de Nietzsche, opina Kaufmann 1988, 153, «no es la ausencia casual de una infección, sino la capacidad para superar enfermedades». De hecho considero la idea de Nietzsche de la salud como uno de los pilares de su arte personal de la transfiguración, porque le permite verse a sí mismo como excepcionalmente sano. Sus continuos sufrimientos aparecen ante el trasfondo de su concepto de salud menos como una lamentable ruina que como prueba de su salud. (Cf. sobre esto expresamente en Brock 2014 y Brock 2016).

31 Aparee como el mayor acontecimiento de toda una época, pero también y especialmente del autor. En el adjetivo «enorme» (ungeheuer), a través del cual Nietzsche define el acontecimiento en FW 125 más próximo y al mismo tiempo demasiado vago, (pues las consecuencias del acontecimiento 
cual todo el libro reluce en un estado de ánimo ambivalente entre fatalidad y promesa - mirando atrás como obra del «agradecimiento de un convaleciente» (FW prólogo 1, OC III 717, KSA 3, 345). Este agradecimiento encuentra resonancia en el tono peculiar del libro La gaya ciencia, en una jovialidad o alegría, que conoce más exactamente el dolor y el tormento, la presión y la angustia del sufrimiento. Por ello habrá que considerarla quizás como una jovialidad y alegría de un grado superior. Pues esa alegría no es superficial, sino que se manifiesta desde la profundidad, que acompaña a un individuo que de nuevo se esfuerza por la altura, y que viene de su punto profundo psicofísico: «[el libro La gaya ciencia] parece escrito en el lenguaje de viento de deshielo: hay en él insolencia, inquietud, contradicción, tiempo de abril, de manera tal que recuerda constantemente tanto la cercanía del invierno como la victoria sobre el invierno, victoria que llegará, que tiene que llegar, que quizás ya ha llegado... De él emana continuamente el agradecimiento, como si hubiera acontecido precisamente lo más inesperado, el agradecimiento de un convaleciente - porque lo inesperado fue la convalecencia. "La gaya ciencia": eso significa las saturnalias de un espíritu que ha resistido paciente una presión terrible, prolongada - paciente, estricto, frío, sin someterse, pero sin esperanza - y que ahora de pronto es invadido por la esperanza, por la esperanza de la salud, por la ebriedad de la convalecencia ${ }^{32}[\ldots]$ Todo este libro no es más que un festejo después de una prolongada privación e impotencia, el alborozo de la fuerza que retorna, de la fe en un mañana y un pasado mañana que vuelve a despertarse, del súbito sentimiento y presentimiento de futuro, de cercanas aventuras, de mares nuevamente abiertos, de metas nuevamente permitidas, nuevamente creídas» (Ibid.: 717). Esto habla en favor de que estas metas no solo tratan de la superación feliz de un episodio grave de enfermedad, sino también del rechazo del nihilismo, que amenazaba con extenderse en el Nietzsche enfermo. Por un lado, está el lenguaje metafórico de la «proximidad del invierno» y de la «victoria sobre el invierno» (ver supra) que en Nietzsche de vez en cuando hace de metáfora para el nihilismo ${ }^{33}$. En la actualidad es más claro aún el nihilismo (rechazado) pero en la afirmación de Nietzsche de una «fe en un mañana y un pasado mañana que vuelve a despertarse» (ver supra), pues el nihilismo es precisamente la pérdida, es decir, la ausencia de una fe semejante: «Nihilismo: falta la meta [...]». (FP IV 241, 1887 9[35], KSA 12, 350). En la enfermedad se impone el nihilismo existencialmente. La lucha entre el sí y el no a la vida se dirime en condiciones desoladoras para del

aún no se pueden prever), se manifiesta lo siniestro del acontecimiento, del que trata el primer apartado del presente artículo.

32 Cf. la embriaguez de la convalecencia con la risa del convaleciente en Z III «El convaleciente»).

33 Cf. Nota 9. 
enfermo con una violencia psico-física. El espíritu de la pesadez, enemigo nihilista por excelencia de Zaratustra, amenaza con conseguir la supremacía durante el episodio de la enfermedad; en el estado de la convalecencia retornan las ganas de seguir viviendo. - y ese ánimo es el «mejor matador» si se trata de reprimir «todo descontento» (Z III «La visión y el enigma», OC IV 164 KSA 4, 198f.) y ahuyentar el espíritu nihilista. En la enfermedad se pone de manifiesto lo frágil que es la vida. El filósofo es consciente de cuánto dependen las imágenes del yo y del mundo, es decir, los juicios sobre el mundo y el yo de estados psicofísicos. Si estamos dispuestos a afirmar la existencia o a no considerarla como una perdición, depende esencialmente de nuestro bienestar corporal ${ }^{34}$. Además, el cuerpo es en Nietzsche el yo, esa unidad sumamente dinámica psicofísica, en la que también juega un papel el espíritu. Pero el espíritu ya no ocupa en la antropología de Nietzsche, que es esencialmente filosofía del cuerpo, el papel principal que tenía en Descartes. No es la esencia del hombre, sino solo un «algo en el cuerpo». El espíritu es una parte del yo, que lo mismo busca «con los ojos de los sentidos», que escucha «con los oídos del espíritu» (Z I «De los despreciadores del cuerpo», OC IV 88 KSA 4, 39f.). Un arte antinihilista de la vida, como el arte de la transfiguración, tiene que tener en cuenta esta idea. Las numerosas observaciones de Nietzsche sobre dietética, sobre las condiciones atmosféricas de los lugares que visitaba, las estaciones del año y las condiciones climáticas, que eran para él soportables o insoportables, agitación y calma, sobre la buena y la mala ascesis, en resumen, sobre el complejo de temas del cuidado de sí son por ello no solo de interés para las biografías de Nietzsche o para los ávidos seguidores del maestro, sino también (o al menos debería ser) para todos aquellos que se ocupan del problema del nihilismo en Nietzsche ${ }^{35}$. Mientras él se preocupa de sí mismo en el sentido descrito, Nietzsche actúa como un artista de la transfiguración. Hace bella su vida ${ }^{36}$. Ahora bien, lo que vale para Nietzsche naturalmente no debe ser vinculante en todo caso para cada uno o cualquier otro. Cuando Nietzsche sostiene- con una mirada de reojo cómica sobre el Jesucristo que camina sobre el agua - «in vino veritas: me parece que también en este punto vuelvo a estar en desacuerdo con todo el mundo por lo que respecta al concepto de "verdad" - en mí el espíritu flota sobre el agua...» (EH «Por qué soy tan

34 Naturalmente también al revés, que mi juicio del yo y del mundo repercuta sobre mi bienestar corporal.

35 Este aspecto de la discusión de Nietzsche con el nihilismo está presente de una manera implícita, pero en mi libro de Nietzsche, sin embargo se le tendria que haber prestado más atención.

36 A eso pertenece también la recuperación de un cierto grado de autonomía o de eficacia en la acción. Nietzsche decide en algún momento «el forzarme a mi mismo a no dejarme cuidar, servir, medicar », sino volver a asumir un papel activo: «Me puse a mí mismo en mis propias manos, me hice a mí mismo volver a estar sano» (EH «Por qué soy tan sabio», 2 OC IV 786, KSA 6, 266) 
inteligente» 1, OC IV 798, KSA 6, 280), eso entonces no se ha de entender como una norma general de no beber vino. Para empezar se trata solo de una observación personal, que sin embargo en este sentido es de interés general, cuando contiene el mensaje de que distintos hombres tienen gustos distintos y soportan bien de modo distinto lo diverso. En eso vuelve a estar la invitación implícita, o al menos la propuesta, a los lectores y lectoras propensos a aclararse sobre su propio gusto, su propia sensibilidad y sus idiosincrasias privadas. Esto puede sonar como algo banal, pero en verdad es más bien basal; pues la vida buena se decide en gran parte en las cosas pequeñas. Para los griegos clásicos eso era algo evidente. Desde los comienzos elementales de la filosofía eso pertenece al arte de la vida. Conviene reflexionar sobre esto: «Tenemos que volver a convertirnos en buenos vecinos de las cosas más cercanas y dejar de apartar la mirada de ellas tan despectivamente como hasta ahora, hacia las nubes y los monstruos nocturnos» (MA II WS 16, OC III 379, KSA 2, 551). El programa del cuidado de sín ${ }^{37}$ de Nietzsche es también una parte del arte antinihilista de la vida, cuyo punto álgido es la transfiguración.

El arte de la transfiguración es exigido, por así decirlo, por el sufrimiento y continuamente provocado. En el nuevo prólogo a La gaya ciencia Nietzsche acentúa su carácter filosófico: «- Se adivina que no quisiera despedirme sin gratitud de ese tiempo de grave padecimiento cuyo beneficio aún hoy no está agotado para mí: del mismo modo en que soy perfectamente consciente de la ventaja que me proporciona mi salud muy cambiante respecto de los rechonchos de espíritu. Un filósofo que ha hecho y vuelve siempre a hacer el camino a través de muchas saludes ha pasado también por otras tantas filosofías: pues no puede hacer otra cosa más que convertir en cada caso su estado en la forma y la lejanía más espiritual, - ese arte de transfiguración es precisamente la filosofía.» (FW V prólogo 3, OC III 719, KSA 3, 349). El arte de transfiguración es filosofía: esta es una afirmación fuerte, que uno debe dejar que se deshaga en la boca. ¿A dónde quiere llegar Nietzsche con esta tesis abrupta? Me parece, que él intenta dos cosas. En primer lugar, es esencial para la filosofía como praxis distanciarse de las cosas, para tener una visión lo más exacta posible de ellas. Quien quisiera hacer justicia a una cosa, debe contemplarla en la medida de lo posible desde todos los lados. Debe, por decirlo así, dar vueltas alrededor del objeto, voltearlo, ponerlo patas arriba, colocarse encima y debajo de él, y en la medida de lo posible echar un vistazo a su interior. Desde esta perspectiva, la filosofía es una especie de arte del ver; de un ver que finalmente se desvanece en conceptos, cuando el filósofo o la filósofa busca conceptualizar lo que acontece. Un hecho, un objeto o una situación, como Nietzsche se expresa, «se convierte su estado en la forma y la

37 Cf. La filosofía como cuidado de sí en Nietzsche, Heinrich 2018, 161-196. 
lejanía más espiritual» (Ibid.). Eso aún no significa, sin embargo, que él de esta manera también ya se ha transfigurado. Nietzsche pone ahora explícitamente el arte de la transfiguración en relación con su enfermedad - y es evidente, que él la transfigura. Asimismo, hubiese sido fundamentalmente posible describir así el tiempo de la larga enfermedad, que a uno le horroriza al leerlo. Nietzsche habría estado en condiciones de imaginársela en toda su terrible profundidad y hubiese podido además fomentar el miedo ante un nuevo episodio de la enfermedad - al menos él ha hecho ya con anterioridad «el camino a través de muchas saludes» (Ibid.), lo que, considerado desde un punto de vista pesimista, no quiere decir otra cosa que antes ya estuvo con frecuencia enfermo. Por lo tanto, Nietzsche también hubiese podido escribir, que él había ya hecho el camino a través de muchas enfermedades. Mientras toma distancia de su fase de enfermedad, logra mantenerla viva, de manera que incluso saca de ella algo positivo. Y mientras él acentúa que ya ha superado muchas fases de la enfermedad (ha pasado por muchas «saludes»), en lugar de poner el dedo en que él debió sufrir muchas de esas fases, él las percibe de su mejor lado. Todo lo ve de la manera más favorable. El arte de la transfiguración es el arte del buen ver como el arte de ver lo bueno en las cosas. Pero eso es, como Nietzsche señala, casi un imperativo que establece la vida - al menos para los filósofos en cuanto artistas de la transfiguración: «No somos ranas pensantes, no somos aparatos registradores con entrañas congeladas, - continuamente tenemos que dar a luz nuestros pensamientos desde nuestro dolor y darles maternalmente todo lo que tenemos en nosotros de sangre, corazón, fuego, placer, pasión tortura, conciencia, destino, fatalidad. Vivir - quiere decir para nosotros convertir en luz y en llama todo lo que somos, y también todo lo que nos toca, no podemos hacer otra cosa. Y por lo que respecta a la enfermedad: ¿no estaríamos casi tentados de preguntar si nos es posible prescindir de ella? Solo el gran dolor es el liberador último del espíritu» (Ibid.). Por lo tanto: el arte de la transfiguración es no solo filosofía, porque en cuanto toma de distancia abarcante y que piensa minuciosamente es una forma de praxis filosófica. Es, eso me parece que quiere expresar Nietzsche, una filosofía en su mejor forma, porque, como él escribe, todo lo que nosotros somos y lo que nos afecta «se convierte en luz y en llama» (Ibid.) Mientras tanto, con luz y llama se desarrollan ideas más sombrías y correspondientemente juicios negativos del mundo y del yo. El arte de la transfiguración es la suprema y mejor forma de filosofía, porque en ella coinciden filosofía y arte. De este modo, se trata de una filosofía de la afirmación de la vida, pues «lo esencial en el arte sigue siendo su cumplida consumación de la existencia, su producción de la perfección y de la plenitud / el arte es esencialmente afirmación, bendición, divinización de la existencia...» (FP IV 522, NL 1888 14[47], KSA 13, 241). 


\section{CONCLUSIÓN}

En el mismo Nietzsche coinciden arte y filosofía, por cierto, de distintas formas. Puede ser correcto que para Nietzsche se transfigure ante todo el mundo, cuando él lo olvida y al sí mismo a través de la inmersión en el espacio auditivo de la música. Entonces, el nihilismo tampoco es ya un tema más, puesto que con la disolución del sujeto en la embriaguez de la música también todo idealismo desaparece de la escena como una diapositiva de juicios de valor negativos. (Cf. van Tongeren 2016b 143) ${ }^{38}$. En la «música del olvido» (OC III 882 FW 367, KSA 3, 616) se abren abismos antinihilistas, es decir, abismos como escondites, abismos de la «perfección»: «Mi melancolía quiere descansar en los escondites y en los abismos de la perfección: para eso necesito la música» (FW 368, OC III 883, KSA 3, 616). Cuando Nietzsche vuelve a salir de tales escondites y abismos, cuando él ha descansado en tales Elíseos y se ha fortalecido, practica el arte de la transfiguración como escritor. Aquí se encuentra él en la cima de su arte ${ }^{39}$. Y cuando escribe, transfigura no solamente su existencia, sino también un poco más allá, la de sus lectoras y lectores. Nietzsche vuelve a colorear el mundo, si no tanto como artista inspirado teománticamente, sí como escritor embriagado artísticamente, ante cuya irradiación el nihilismo cae de rodillas. Y esto ocurre quizá de un modo especial, cuando él no tiene el nihilismo tras él y fuera de él (Cf. FP IV 489, 1887, KSA 13, 11[411], 190), sino puesto en medio de él. Pues para dar la última palabra a otro filósofo poeta y experto en cuestiones del dolor: «¿Qué es un poeta? Un hombre infeliz, que conlleva profundos tormentos en su corazón, pero sus labios están formados de tal manera que, mientras derrama sobre ellos gritos y suspiros, suena igual que una música bella». ${ }^{40}$

[Traducción: Luis Enrique de Santiago Guervós]

\section{BIBLIOGRAFÍA}

ANDERS, G., (2010), Die Antiquiertheit des Menschen. Band 1. Über die Seele im Zeitalter der zweiten industriellen Revolution: München.

BROCK, E., (2014), «Vom Schönmachen aller Dinge. Nietzsches Kunst der Transfiguration als antinihilistische Lebenskunst», en: Nietzscheforschung 21, pp. 197-208.

38 Van Tongeren 2016b llama la atención sobre el significado eminente de la música para Nietzsche, es decir, para su arte de la transfiguración.

39 Y esto significa una altura especialmente elevada: «Quizás podamos permitirnos observar que Nietzsche como autor de la lengua alemán y de la sintaxis europea ha alcanzado la cima» (Sloterdijk 2001, 68).

40 Kierkegaard 1956, 19. 
BROCK, E., (2015), Nietzsche und der Nihilismus, Berlin/München/Boston.

BROCK, Eike (2016), «Mit dem Leiden leben. Kierkegaard, Nietzsche und Jaspers als Leidenskünstler», en Gödde, Günter/Loukidelis, Nikolaos (Hg.): Nietzsche und die Lebenskunst. Ein philosophisch-psychologisches Kompendium, Stuttgart, S. pp. 95-105.

BROCK, E., (2017), «Nietzsches Dionysos-Dithyrambus Zwischen Raubvögeln als Ausdruck einer nihilistischen Seelenkrise», en Benne, Christian/Zittel, Claus (Hg.): Nietzsche und die Lyrik. Ein Kompendium, Stuttgart, p. 350-359.

BROCK, E., (1999), «Scribo ergo sum'.Lesen und Schreiben als identitätsbildende Maßnahmen bei Friedrich Nietzsche und Stanley Cavell» en: Nietzscheforschung 25 (2018), 173-198.

GERHARD, V., (1999), Nietzsche, München.

DÜRRENMATT, F., (1992), Der Richter und sein, Henker: Zürich.

ERNST, G., (2016), «Philosophie als Wissenschaft oder als Lebenskunst. Zeitgenössische Perspektiven», en Ders. (Hg.): Philosophie als Lebenskunst. Antike Vorbilder, moderne Perspektiven, Frankfurt a. Main, pp. 300-321.

GILLESPIE, M. A., (!995), Nihilism before Nietzsche, Chicago,London.

HEINRICH, J., (2018), Individualität, Subjektivität und Selbstsorge bei Nietzsche. Eine Analyse im Gespräch mit Foucault, Berlin,Boston.

KAST, C., (2019), Friedrich Nietzsches Ja zum Leben, Würzburg.

KIERKEGAARD, S., (1956), Entweder Oder. Erster Band, Gesammelte Werke 1. Abt., hrsg. von Emanuel Hirsch und Hayo Gerdes, Düsseldorf, Köln.

LERCHNER, T., (2013), «Die Welt als Vorstellung: Arthur Schopenhauer und der theatralische Blick aufs Dasein», in: Schopenhauer-Jahrbuch vol. 94, pp. 53-75.

MÖBUSS, S., (2015) Existenzphilosophie. Band I. Von Augustinus bis Nietzsche, Freiburg, München.

MORGENSTERN, M., (2018), Vom Vorbild zum Antipoden. Die Bedeutung Schopenhauers für Nietzsches Denken, Würzburg.

MÜLLER, R., (2015), Vom Verlust der Bedeutungsschwere. Zeitdiagnostische Grundlegung einer philosophischen Theologie im Zeitalter des Nihilismus, Dresden.

NIETZSCHE, F., (1988), Sämtliche Werke. Kritische Gesamtausgabe (KSA), 15 Bände, hrsg. von Giorgio Colli und Mazzino Montinari, 2. durchges. Aufl.., München/Berlin/New York.

OTTMANN, H., (1999), Philosophie und Politik bei Nietzsche, Berlin/New York.

PLATON, (2019), Phaidros, Hamburg.

RANK, O., (1929), Technik der Psychoanalyse II. Die Analytische Situation, Leipzig/ Wien.

RIEDEL, M., (1978), «Nihilismus» en Geschichtliche Grundbegriffe. Historisches Lexikon zur politisch sozialen Sprache in Deutschland, hrsg. von Otto Brunner, Werner Conze, Reinhart Kosseleck, Band 4, Stuttgart, pp. 371-441.

SCHOPENHAUER, A., (1972) Die Welt als Wille und Vorstellung I. Sämtliche Werke. Band 2, hrsg. von Arthur Hübscher, Wiesbaden.

SLOTERDIJK, P., (2001), «Über die Verbesserung der guten Nachricht» en Nietzsches fünftes Evangelium, Frankfurt a. Main. 
VAN TONGEREN, P, (2016a), «Was uns Nietzsches Ästhetik für die Frage der Lebenskunst lehrt» en Gödde, Günter/Loukidelis, Nikolaos/Zirfas, Jörg (Hg.): Nietzsche und die Lebenskunst. Ein philosophisch-psychologisches Kompendium, Stuttgart, pp. 118-125.

VAN TONGEREN, P., (2016b), «Die "Musik des Vergessens" und das "Ideal eines übermenschlichen Wohlwollens". Über Nihilismus, Transfiguration und Nihilismus bei Nietzsche» en Nietzsche Studien, vol. 45 (2016), pp. 143-157.

WEISCHEDEL, W., (1983), Der Gott der Philosophen. Grundlegung einer philosophischen Theologie im Zeitalter des Nihilismus. Zwei Bände in einem Band, Darmstadt.

VATTIMO, G., (2004), Jenseits des Christentums. Gibt es eine Welt ohne Gott?, München. 